Printed in Great Britain

\title{
Taxonomic Relationships of Xanthomonas uredovorus
}

\author{
BY A. C. HAYWARD \\ Commonwealth Mycological Institute, Kew \\ AND W. HODGKISS \\ Torry Research Station, Aberdeen
}

(Received 3 March 1961)

\section{SUMMARY}

The cultural and physiological characteristics of some Xanthomonas spp. that are typical of the genus were compared with two atypical species, Xanthomonas uredovorus and $X$. stewartii. Electron microscopic studies of $X$. uredovorus, prepared by two methods, show that this organism possesses peritrichous flagella. This fact, together with evidence of the fermentative metabolism of carbohydrates, should exclude this bacterium from the genus $X$ anthomonas. The interpretation of electron micrographs is discussed, and the systematic position of $X$. uredovorus and $X$. stewartii.

\section{INTRODUCTION}

From the systematic examination of numerous xanthomonads from culture collections and of fresh isolates from diseased plant material, and from a comparison of these with published descriptions of the genus Xanthomonas (Burkholder \& Starr, 1948; Dowson, 1957; Dye, 1959) it became obvious that the definition of the genus required clarification. At least two species, $X$. uredovorus, a parasite of the uredia of cereal rusts, and $X$. stewartii the cause of Stewart's disease of sweet corn, were thought to have a number of characteristics which should exclude them from the genus. This study was undertaken in order to compare some physiological characteristics of a selection of seven Xanthomonas spp. with X. stewartii and X. uredovorus, and thus elucidate some fundamental differences between them. An electron microscopic study of $\boldsymbol{X}$. uredovorus was carried out to provide unequivocal evidence of the mode of flagellation. In the original publication (Pon et al. 1954) $X$. uredovorus was described as possessing a single polar flagellum, and by this criterion, together with pigmentation, the bacterium was classified in the genus Xanthomonas.

\section{METHODS}

Source of cultures. The following cultures were obtained from the National Collection of Plant Pathogenic Bacteria (NCPPB, Harpenden, Hertfordshire): $X$ anthomonas stewartii NCPPB 67, NCPPB 449, $X$. uredovorus NCPPB 391, $X$. phaseoli NCPPB 557, $X$. campestris NCPPB 279, $X$. vasculorum NCPPB 795 (from Madagascar), NCPPB 796 (from Mauritius), $X$. vesicatoria NCPPB 701, $X$. nigromaculans f.sp. zinniae NCPPB 799, $X$. malvacearum NCPPB 634. Three other cultures of $X$. uredovorus were received from Professor M. P. Starr (University of California); these strains, XU 102, XU 103 and XU 104 have been deposited in the 
National Collection of Plant Pathogenic Bacteria and given the accession numbers 800, 801 and 802. Three cultures of $X$. malvacearum from C. Logan (Empire Cotton Growing Corporation, Uganda) and two freshly isolated strains of $X$. pruni from Professor H. H. Thornberry (University of Illinois), were included in the group of strains used for systematic examination.

Staining reactions. Weigert's modification of Gram's method was used. The presence of sudanophilic inclusions in heat-fixed smears of the test bacteria was determined by the method of Burdon (1946), but without clarification of the smears stained with Sudan Black B (G. Gurr Ltd.) by dipping in xylene. After staining with the Sudan stain for 10-15 min. the preparation was washed under a gentle stream of tap water. Smears for Sudan staining were prepared after incubation for 3 and 6 days on glucose peptone agar of the following composition: glucose, 20.0 g.; $\mathrm{K}_{2} \mathrm{HPO}_{4}, 0.5 \mathrm{~g}$.; $\mathrm{MgSO}_{4} .7 \mathrm{H}_{2} \mathrm{O}, \mathbf{0 . 2 5}$ g.; peptone (Oxo Ltd.) 5.0 g.; agar (Davis Gelatine Ltd.), $20 \cdot 0$ g.; distilled water 11. ; pH about $\mathbf{7 \cdot 2}$.

Motility. This was determined periodically in a semi-solid medium (3.0 g. agar/l.), using hanging drop preparations.

Oxidation v. fermentation of carbohydrates. The medium of Hugh \& Leifson (1953) was modified for use with the weakly oxidative plant pathogenic bacteria, as follows: peptone (Oxoid), 1.0 g.; $\mathrm{NH}_{4} \mathrm{H}_{2} \mathrm{PO}_{4}, 1.0$ g.; $\mathrm{MgSO}_{4} .7 \mathrm{H}_{2} \mathrm{O}, 0 \cdot 2$ g.; $\mathrm{KCl}, 0 \cdot 2$ g.; agar, $3.0 \mathrm{~g}$; ; bromthymol blue $0.03 \mathrm{~g}$; ; distilled water $1 \mathrm{1}$.; $\mathrm{pH}$ about $\mathbf{7 \cdot 2}$. Five ml. of a $10 \%(\mathrm{w} / \mathrm{v})$ solution of glucose was added to $45 \mathrm{ml}$. quantities of the molten agar base which was dispensed in sterile plugged test tubes $(5 \times 0.4$ inch) to a depth of about $\mathbf{1 . 5}$ in. Sterile liquid paraffin (B.P. grade) was used as a seal, following stab inoculation of the test bacteria from agar cultures. Salicin $(10.0 \mathrm{~g} . / \mathrm{l})$ was sterilized with the medium. Inoculated tubes were examined for a period of 14 days.

Lipase. The method of Sierra (1957) was used; the cultures were discarded after incubation for 6 days.

Hydrolysis of soluble starch, gelatin and casein. The following agar medium was dispensed in $45 \mathrm{ml}$. quantities in $2 \mathrm{oz}$. bottles : peptone (Oxoid), $5 \cdot 0 \mathrm{~g}$.; yeast extract (Difco), 3.0 g.; agar, 20.0 g.; distilled water, 1 l.; adjusted to pH 7.2. Five ml. quantities of $4.0 \%(\mathrm{w} / \mathrm{v})$ gelatin (British Drug Houses Ltd.), $4.0 \%(\mathrm{w} / \mathrm{v})$ casein (Judex Ltd., light white soluble), or $\mathbf{2 \cdot 0} \%$ (w/v) soluble starch (British Drug Houses Ltd., Analar) were added to the molten agar base from which three plates were poured. Three or four organisms were inoculated to each plate, into the centre of $0.5 \mathrm{~cm}$. diameter cavities made with a surface sterilized cork borer. After incubation for 6 days starch plates were flooded with Gram's iodine solution and gelatin plates with acid mercuric chloride solution (Frazier, 1926). Zones of hydrolysis were recorded.

Aesculin hydrolysis. The liquid and solid media of Sneath (1960) were used and observed for blackening and loss of fluorescence for a period of 14 days.

Production of $\mathrm{H}_{2} \mathrm{~S}$ and indole. Peptone water supplemented with casein hydrolysate (British Drug Houses Ltd., Laboratory reagent) 1.0 g./l., and L-cysteine hydrochloride, $0 \cdot 1 \mathrm{~g}$./1. was dispensed in $5 \mathrm{ml}$. quantities in $\frac{1}{2} \mathrm{oz}$. screw-capped bottles. Lead acetate papers were held over the medium by the screw cap which was kept loose. At 6 days final observations were made for $\mathrm{H}_{2} \mathrm{~S}$ production, and indole was tested for by addition of ether and Ehrlich's rosindole reagent (Mackie \& McCartney, 1960, p. 609). For $\mathrm{H}_{2} \mathrm{~S}$ production consistent results were only obtained 
by using a relatively massive inoculum, i.e. one loopful of growth on glucose peptone agar. From small inocula some Xanthomonas spp. gave inconsistent results.

Urease. The method of Christensen (1946) was used, with incubation for 14 days.

Oxidase. Kovacs's method (1956) was used.

Catalase. Loopfuls of agar growth were emulsified in 10 vol. $-\mathrm{H}_{2} \mathrm{O}_{2}$ on a slide and examined microscopically for evolution of oxygen.

Voges-Proskauer reaction. This was made at 6 days in standard glucose phosphate medium, using Barritt's modification (Mackie \& McCartney, 1960).

Salt tolerance. The following medium was dispensed in $10 \mathrm{ml}$. quantities in $1 \mathrm{oz}$. screw-cap bottles, and inoculated with two drops of a light suspension of the test organism in distilled water: peptone (Oxoid), 5.0 g.; sucrose (British Drug Houses Ltd., Analar), 5.0 g.; $\mathrm{K}_{2} \mathrm{HPO}_{4}, 0.5 \mathrm{~g}$.; $\mathrm{MgSO}_{4}, 0.25 \mathrm{~g}$., sodium chloride (Analar),

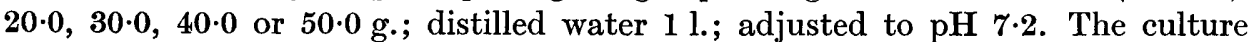
medium was examined for turbidity during incubation for 14 days.

Nitrite formation from nitrate and nitrite destruction. A medium of the following composition was used: peptone (Oxoid), 10.0 g.; $\mathrm{K}_{2} \mathrm{HPO}_{4}, 5.0 \mathrm{~g}$; ; yeast extract (Difco), 1.0 g.; $\mathrm{KNO}_{3}, 1.0$ g. or $\mathrm{NaNO}_{2}, 0 \cdot 1 \mathrm{~g}$.; agar, 3.0 g.; distilled water, 1 l.; adjusted to $\mathrm{pH} 7 \cdot 0 ; 10 \mathrm{ml}$. medium per 1 oz. screw-capped bottles. At 5 days tests for nitrite formation or nitrite destruction were made by standard procedures.

Growth temperatures. Two drops of a light suspension of organisms in distilled water were added to glucose peptone agar slopes maintained in a water bath at $40^{\circ}$ or $37^{\circ}$ for 2 days. Otherwise all cultures were incubated at $28^{\circ}$ for the period of test.

Electron microscopy. One culture of Xanthomonas uredovorus, strain XU 102, was examined extensively under the electron microscope by one of us (W.H.). Cultures for electron microscopy were grown on nutrient agar slopes and incubated at $20^{\circ}$ for 3 days or at $25^{\circ}$ for $24 \mathrm{hr}$. The resultant growth was suspended in distilled water and washed three times by centrifugation. The washed suspensions were then stored overnight at $+5^{\circ}$, a procedure which causes partial lysis and consequently causes the cell contents to shrink more readily upon drying. Two methods of preparation, metal-shadowing and phosphotungstic acid 'staining', were used. For the former, the washed suspensions were mounted on formvar films and shadowed with gold-palladium at an angle of $15^{\circ}$. For the phosphotungstic acid preparations (Brenner \& Horne, 1959) an equal volume of $2 \%(\mathrm{w} / \mathrm{v})$ aqueous phosphotungstic acid solution (adjusted to $\mathrm{pH} \mathbf{7 \cdot 4}$ with $\mathrm{KOH}$ ) was added to washed suspensions and the resultant mixture mounted on carbon films. The specimens were examined in a Siemens Elmiskop I using the single condensed system with a $200 \mu$ condenser aperture and a $50 \mu$ objective aperture. Electron micrographs were taken at initial magnifications of $\times 8000$ and $\times 10,000$ on Ilford N 50 plates.

\section{RESULTS}

All the bacteria examined were unequivocally Gram-negative in young (16 hr.) cultures and did not form prominent polar or central, refractile, sudanophilic inclusions on glucose peptone agar after incubation for 3 or 6 days. This is in accordance with previous observations (Hayward, 1960). With the known exception of Xanthomonas albilineans, bacteria of the genus Xanthomonas do not form sudano- 
philic inclusions in culture on a medium containing utilizable carbohydrate, as do many pseudomonads (Morris \& Roberts, 1959).

There were differences between the cultural characteristics of the Xanthomonas spp. on the one hand and the cultures of $X$. stewartii and $X$. uredovorus on the other. The latter did not produce the raised, convex, shiny, slimy, mucoid colonies which are typical of the majority of Xanthomonas spp. grown on an agar medium containing glucose or sucrose. The exception in this study was the Madagascar strain of $X$. vasculorum which was non-mucoid, in common with several other strains of this species. Elrod \& Braun (1947) noted the increase in degree of mucoidness with serial transfer on media rich in carbohydrate, an increase we have noted. This increase in mucoidness was observed in some strains which were non-mucoid on first isolation. All the bacteria examined were yellow in the mass on agar.

The cultures examined were catalase positive. The Kovacs oxidase test did not give unequivocal results on different media and after different periods of incubation: on Difco nutrient agar cultures at 2 days all the Xanthomonas spp. were positive, i.e. they gave a strong colour reaction in less than 30 sec., while the cultures of $X$. uredovorus and $X$. stewartii were negative at $\mathbf{3 0}$ sec. However, on a medium

Table 1. Characters of some Xanthomonas spp., Xanthomonas stewartii and Xanthomonas uredovorus

\begin{tabular}{|c|c|c|c|}
\hline Characteristic & $\begin{array}{c}\text { Xanthomonas spp. } \\
\text { (7 species, } \\
12 \text { strains) }\end{array}$ & $\begin{array}{l}X . \text { stewartii } \\
\text { (2 strains) } \\
\text { NCPPB } 449 \\
\text { NCPPB } 67\end{array}$ & $\begin{array}{l}X . \text { uredovorus } \\
\text { (4. strains) }\end{array}$ \\
\hline ism of glucose & $\begin{array}{c}\stackrel{+}{\text { Oxidative }} \\
\text { (3-6 days) }\end{array}$ & $\begin{array}{c}- \\
\text { Fermentative, } \\
\text { anaerogenic } \\
(24-48 \mathrm{hr} .)\end{array}$ & $\begin{array}{c}+ \\
\text { Fermentative, } \\
\text { anaerogenic } \\
(\mathbf{1 2 - 2 4} \mathbf{~ h r} .)\end{array}$ \\
\hline sm of salicin & - & - & Fermentative, anaerogenic \\
\hline sis of 'Tween 80' & + & $\rightarrow$ & + \\
\hline starch hydrolysis & $+\left(\frac{0}{18}\right)$ & - & - \\
\hline hydrolysis & + & - & + \\
\hline hydrolysis & + & - & Weak + \\
\hline hydrolysis & + & - & + \\
\hline m cysteine & + & - & - \\
\hline from nitrate & - & 一 & + \\
\hline destruction & - & - & - \\
\hline ce of sodium chloride & $\mathbf{2}-\mathbf{3} \%$ & $5 \%$ & $5 \%$ \\
\hline & - & - & - \\
\hline Proskauer reaction & - & $-(449)$ & $+(67)$ \\
\hline production & - & - & + \\
\hline at $37^{\circ}$ & + & + & + \\
\hline at $40^{\circ}$ & - & - & - \\
\hline
\end{tabular}

$-=$ Negative reaction, $+=$ positive reaction.

Soluble starch hydrolysis: for Xanthomonas spp. zone diameter 36.0-56.0 $\mathrm{mm}$. The two cultures of $X$. pruni did not hydrolyse starch, the Madagascar strain of $X$. vasculorum did not produce a clearly defined zone of hydrolysis but showed a trace of activity.

Casein hydrolysis: for Xanthomonas spp. zone diameter 17.0-46.0 mm. The cultures of $X$. uredovorus did not produce a clearly defined zone of hydrolysis but a decrease in the opacity of the medium in a zone $10.0 \mathrm{~mm}$. diameter.

Gelatin hydrolysis : for Xanthomonas spp. zone diameter $20.0-46.0 \mathrm{~mm}$., for the cultures of $\boldsymbol{X}$. uredovorus c. $15 \cdot 0$ to $c .23 \cdot 0 \mathrm{~mm}$. 
containing $2 \%(\mathrm{w} / \mathrm{v})$ glucose or glycerol the Kovacs reaction given by some of the $X$ anthomonas spp. was retarded and often indistinguishable from the reaction given by $\boldsymbol{X}$. uredovorus and $X$. stewartii. On a rich tomato juice agar medium the cultures of $X$. uredovorus and $X$. stewartii gave a positive oxidase reaction.

In the modified Hugh \& Leifson (1953) technique Xanthomonas spp. produced an indicator change in the top $1 \mathrm{~cm}$. of medium after incubation for 3-6 days, whereas the cultures of $X$. uredovorus produced an indicator change throughout the depth of the medium in 12-24 hr. and $X$. stewartii in 24-48 hr. Other characters are given in Table 1 .

\section{Electron microscopy of Xanthomonas uredovorus strain $X U 102$.}

Shadow-cast specimens showed that the organisms usually possess one or two lateral flagella (Pl. 1, figs. 1, 2, 3); occasionally more flagella were seen (Pl. 1, figs. 4, 5 and 6). No organisms with polar flagella were seen. The phosphotungstic acid preparations were most interesting as these illustrate the difficulties encountered in the interpretation of flagella-preparations. Plate 2, fig. 7, is easy to interpret and clearly shows the lateral insertion of the flagellum. However, were this organism to be rotated on its own axis through $90^{\circ}$ the flagellum could appear to be polar in origin, particularly in shadow-cast specimens. Plate 3, fig. 8, illustrates the true path of the flagellum and the origin of the flagellum in an organism in exactly this position.

Plate 4, fig. 9, shows a shadow-cast specimen in which the true path of the flagellum can be traced. Partial lysis and the consequent amount of shrinkage of cell contents allows the true (lateral) position of origin of the flagellum to be clearly defined.

\section{DISCUSSION}

The electron micrographs indicate that the original authors (Pon et al. 1954) were in error in their interpretation of their electron micrographs. Critical examination of their published micrograph (Pon et al. 1954) reveals the possible source of this error. The complete organism shown in the micrograph is full of cell material, it is metal-shadowed and there is a considerable amount of debris near the pole. The true path of the flagellum is probably obliterated by the metal shadowing (cf. Pl. 3, fig. 8; Pl. 4, fig. 9). In addition the Pon et al. micrograph includes part of another cell in which the origin of the flagellum is undoubtedly lateral. Attention has already been drawn to the difficulties of interpretation of flagella stains when using the optical microscope (Hodgkiss, 1961). It is apparent from the present results that electron-micrographs of bacterial flagella require equally careful interpretation. As an illustration, an overexposed negative or an overexposed and/or overdeveloped print of Pl. 3, fig. 8 could show a 'polar' flagellum.

The occurrence of mixed polar and peritrichous forms in pure cultures of organisms as described by Leifson \& Hugh (1953), Sneath (1956) and Sreenivasan \& Venkataraman (1956) merits discussion. Careful electron microscopic studies at Torry Research Station of various organisms have so far failed to yield similar results. It would appear that the interpretation of results requires special care in opticalmicroscopic examinations of flagella stains when detail such as that seen in Pls. 2, 3, 4 cannot possibly be resolved.

Together with the evidence provided by electron microscopy, the results of the biochemical tests show that Xanthomonas uredovorus has no place in the Pseudo- 
monadaceae, but should be included in the family Enterobacteriaceae. X. uredovorus is not a plant parasite, but a parasite of the fructifications of a fungal pathogen and the bacterial genus Erwinia is so defined in the 7th edition (1957) of Bergey's Manual to include only plant pathogens. However, $\boldsymbol{X}$. uredovorus is closely related to the anaerogenic Erwinia spp., to which genus we propose that this bacterium be transferred.

Misgivings about the classification of Xanthomonas uredovorus were expressed by Lovrekovich \& Klement (1960) in a study of the tolerance of triphenyltetrazolium chloride by organisms of several genera of bacterial plant pathogens. In the genus $X$ anthomonas, $X$. uredovorus strains, and also $X$. stewartii, were markedly more tolerant than the other species tested.

Xanthomonas uredovorus is related to Erwinia lathyri (Manns \& Taubenhaus) Holland as described by Graham (1958), who summarized the principal characters of this bacterium as follows: coliform (i.e. fermentative) metabolism of carbohydrates, without gas formation, peritrichous flagellation, positive gelatin liquefaction, Voges-Proskauer and nitrate reduction both usually positive, formation of a yellowish pigment on many agar media. Although discredited as a plant pathogen (Graham, 1958), E. lathyri or its close relatives are regularly isolated from moribund plant material. They occur as saprophytes on plants and plant debris and in the soil, which is also characteristic of Xanthomonas uredovorus according to Pon et al. (1954). E. lathyri grows more rapidly on isolation media than xanthomonads, and consequently has often been implicated, mistakenly, as the cause of plant disease. In differentiating the Gram-negative bacteria on plant material the technique of Hugh \& Leifson (1953) has proved invaluable for screening a large number of bacteria, and in avoiding the confusion between $E$. lathyri and Xanthomonas spp.

The definition of the genus Xanthomonas (Dowson, 1957; Dye, 1959) should be modified to include only bacteria with an oxidative metabolism of glucose, and thus exclude organisms such as $X$. stewartii and $X$. uredovorus which are clearly distinct from Xanthomonas on other grounds (see Table 1). X. stewartii, in addition to having a fermentative metabolism of carbohydrates, is non-motile, has a high salt tolerance (Burkholder \& Starr, 1948), does not hydrolyse aesculin, potato starch or gelatin, and does not produce hydrogen sulphide in a medium containing cysteine. However, the systematic position of $X$. stewartii is obscure, and without detailed comparative study with other yellow Gram-negative bacteria, for example, of the genus Flavobacterium, it is not yet possible to propose a change in the classification of this organism. It has long been recognized as an atypical xanthomonad (Burkholder \& Starr, 1948), and may be a degenerate member of the Enterobacteriaceae.

The authors wish to thank Professor H. H. Thornberry, Professor M. P. Starr, Mr C. Logan and Mr R. A. Lelliott (Curator of the National Collection of Plant Pathogenic Bacteria, Harpenden, Hertfordshire) for generously providing the cultures used in this investgation. The electron microscopy described in this paper was carried out as part of the programme of the Department of Scientific and Industrial Research. 


\section{REFERENCES}

Brenner, S. \& Horne, R. W. (1959). A negative staining method for high resolution microscopy of viruses. Biochim. biophys. Acta, 34, 103.

Burdon, K. L. (1946). Fatty material in bacteria and fungi revealed by staining dried, fixed slide preparations. J. Bact. 52, 665 .

Burkholder, W. H. \& Starr, M. P. (1948). The generic and specific characters of phytopathogenic species of Pseudomonas and Xanthomonas. Phytopathology, 38, 494.

Christensen, W. B. (1946). Urea decomposition as a means of differentiating Proteus and Paracolon organisms from each other and from Salmonella and Shigella types. J. Bact. 52, 461.

Dowson, W. J. (1957). Plant Diseases due to Bacteria, 2nd ed. Cambridge University Press.

Dye, D. W. (1959). The genus Xanthomonas. Comm. Phytopath. Neres, $5,1$.

Elrod, R. P. \& BraUn, A. C. (1947). Serological studies of the genus Xanthomonas. I. Cross agglutination relationships. J. Bact. 53, 509.

Frazier, W. C. (1926). A method for the detection of changes in gelatin due to bacteria. J. infect. Dis. 39, 302.

Graham, D. C. (1958). The status of Erwinia lathyri and related bacteria. Comm. Phytopath. Neres, 4, 49.

Hayward, A. C. (1960). A method for characterizing Pseudomonas solanacearum. Nature, Lond. 186, 405.

Hodgkiss, W. (1961). The interpretation of flagella stains. J. appl. Bact. (in the Press).

Hugr, R. \& Leifson, E. (1953). The taxonomic significance of fermentative versus oxidative metabolism of carbohydrates by various Gram-negative bacteria. J. Bact. 66, 24.

Kovacs, N. (1956). Identification of Pseudomonas pyocyanea by the oxidase reaction. Nature, Lond. 178, 703.

LEIFSON, E. \& HUGH, R. (1953). Variation in shape and arrangement of bacterial flagella. J. Bact. 65, 263.

Lovrekovich, L. \& KLement, Z. (1960). Triphenyltetrazolium chloride tolerance of phytopathogenic bacteria. Phytopath. Z. 39, 129.

Mackie, T. J. \& McCartney, J. E. (1960). Handbook of Practical Bacteriology, 10th ed. Edinburgh: Livingstone.

Morris, M. B. \& Roberts, J. B. (1959). A group of pseudomonads able to synthesize poly- $\beta$-hydroxybutyric acid. Nature, Lond. $183,1538$.

Pon, D. S., Townsend, C. E., Wessman, G. F., Schmitt, C. G. \& Kingsolver, C. M. (1954). A Xanthomonas parasitic on uredia of cereal rusts. Phytopathology, 44, 707.

Sierra, G. (1957). A simple method for the detection of lipolytic activity of microorganisms and some observations on the influence of the contact between cells and fatty substrates. Antonie van Leeurwenhoek J. Microbiol. Serol. 23, 15.

Sneath, P. H. A. (1956). The changes from polar to peritrichous flagellation in Chromobacterium spp. J. gen. Microbiol. 15, 99.

Sneath, P. H. A. (1960). A study of the bacterial genus Chromobacterium. Iowa St Coll. J. Sci. 34, 243.

Sreenivasan, A. \& Venkataraman, R. (1956). Occurrence of paracolon bacteria in a tropical marine environment and their classification. Nature, Lond. 178, 547. 


\section{EXPLANATION OF PLATES}

All preparations were of cultures of Xanthomonas uredovorus, strain XU 102 grown on nutrient agar at $20^{\circ}$ for 3 days.

The scale marked on figures $=1 \cdot 0 \mu$.

\section{Plate 1}

Fig. 1. Gold palladium shadow at $15^{\circ} . \times 16,000$. Neg. no. 454 .

Fig. 2. Gold palladium shadow at $15^{\circ} . \times 25,000$. Neg. no. 452.

Fig. 3. Gold palladium shadow at $15^{\circ} . \times 16,000$. Neg. no. 481 .

Fig. 4. Gold palladium shadow at $15^{\circ} . \times 20,000$. Neg. no. 458.

Fig. 5. Gold palladium shadow at $15^{\circ} . \times 24,000$. Neg. no. 456 .

Fig. 6. Phosphotungstic acid preparation. $\times 32,000$. Neg. no. 472 .

\section{Prate 2}

Fig. 7. Phosphotungstic acid preparation. $\times 32,000$. Neg. no. 472 .

\section{Plate 3}

Fig. 8. Phosphotungstic acid preparation. $\times 32,000$. Neg. no. 478 .

\section{Plate 4}

Fig. 9. Gold palladium shadow at $15^{\circ} . \times 32,000$. Neg. no. 482 . 

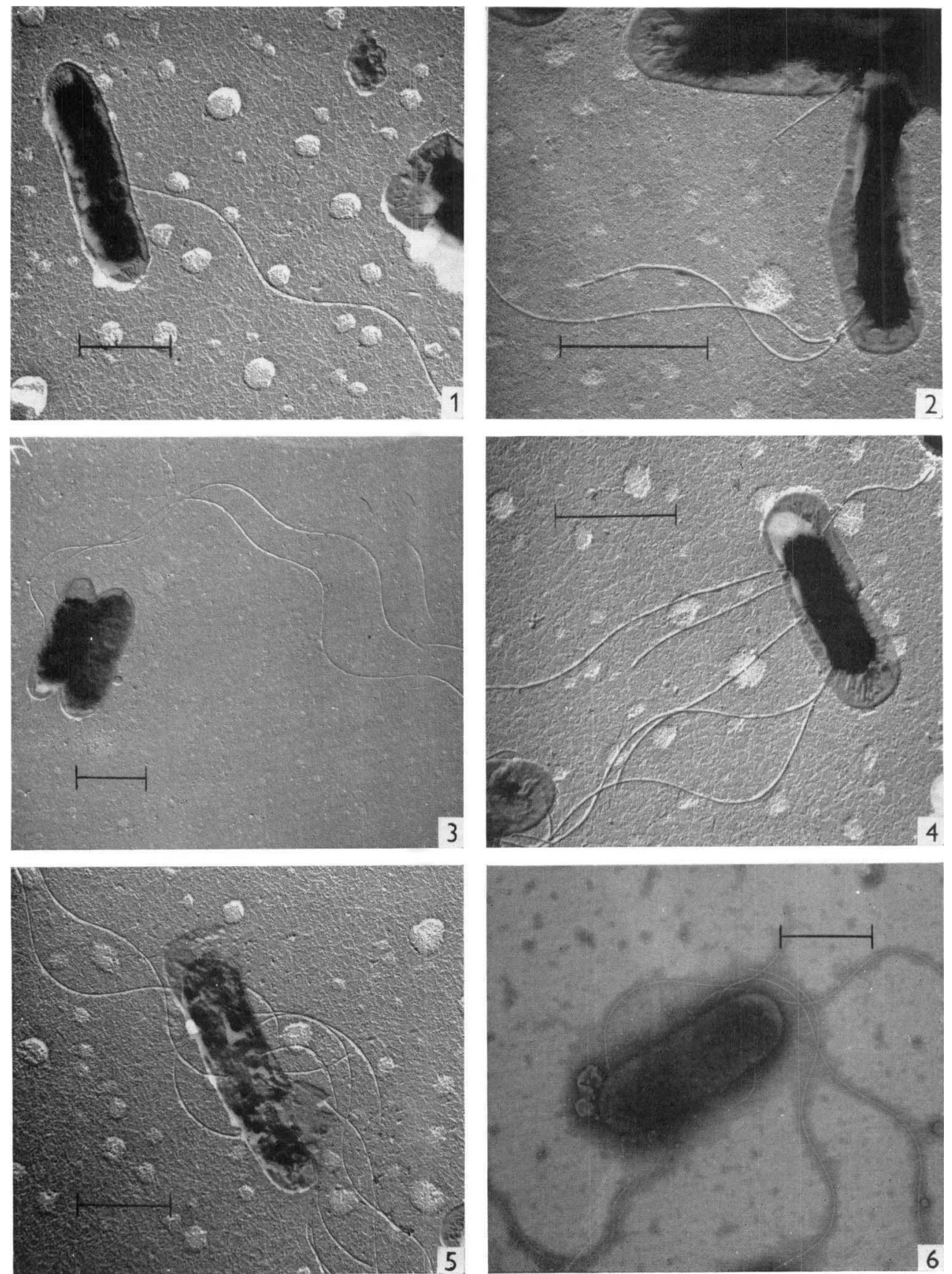


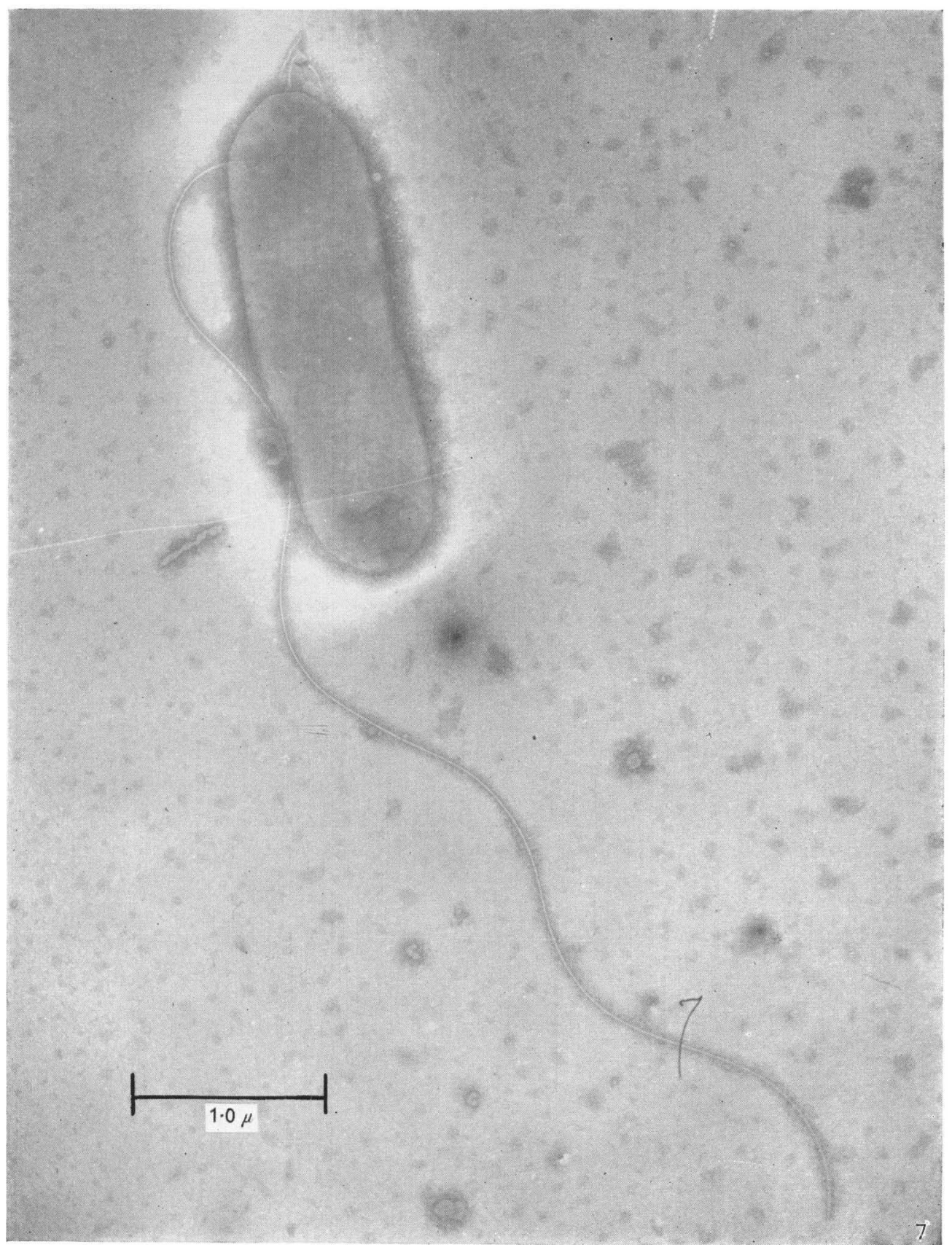

A. C. HAYWARD AND W. HODGKISS 


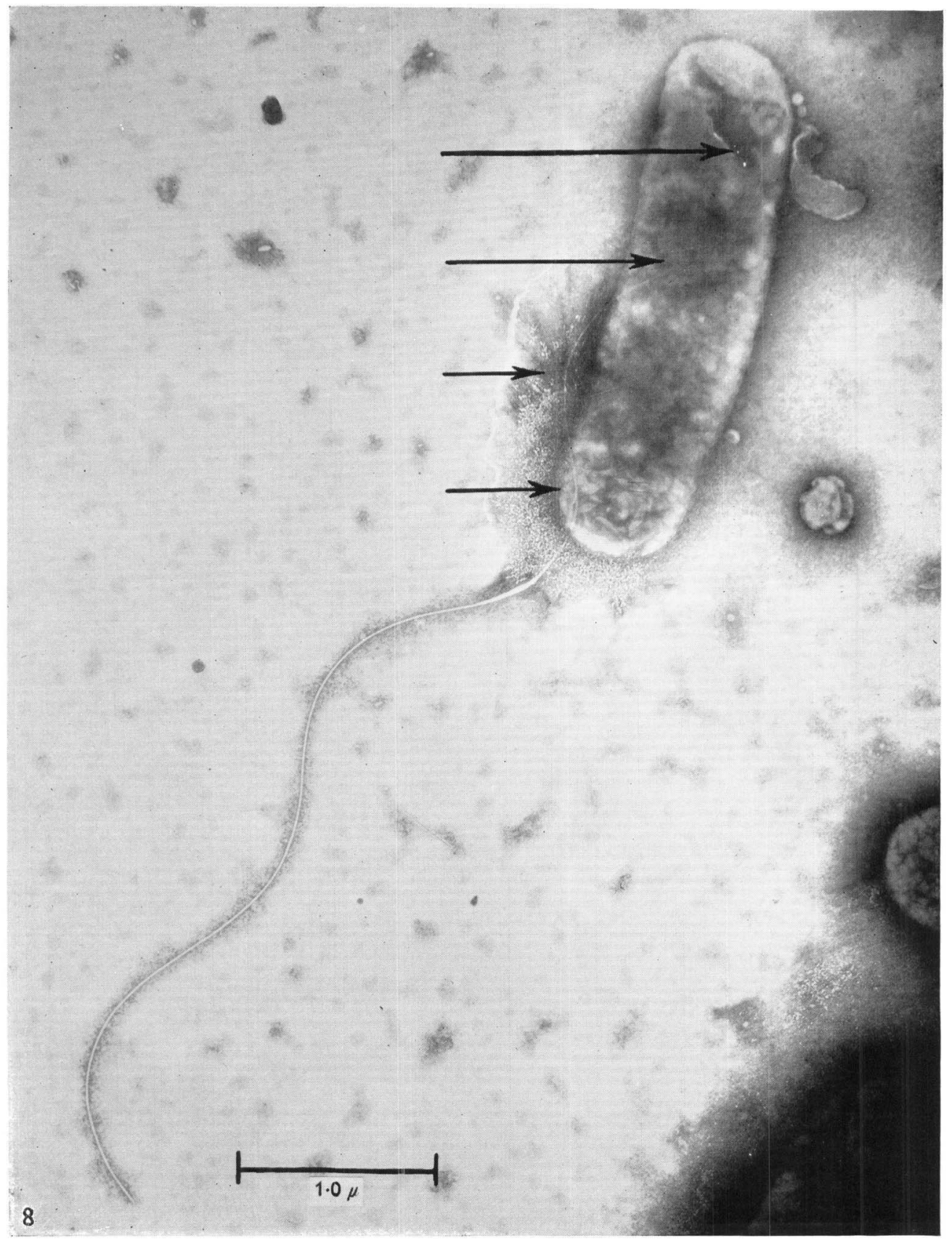

A. C. HAYWARD AND W. HODGIISS 


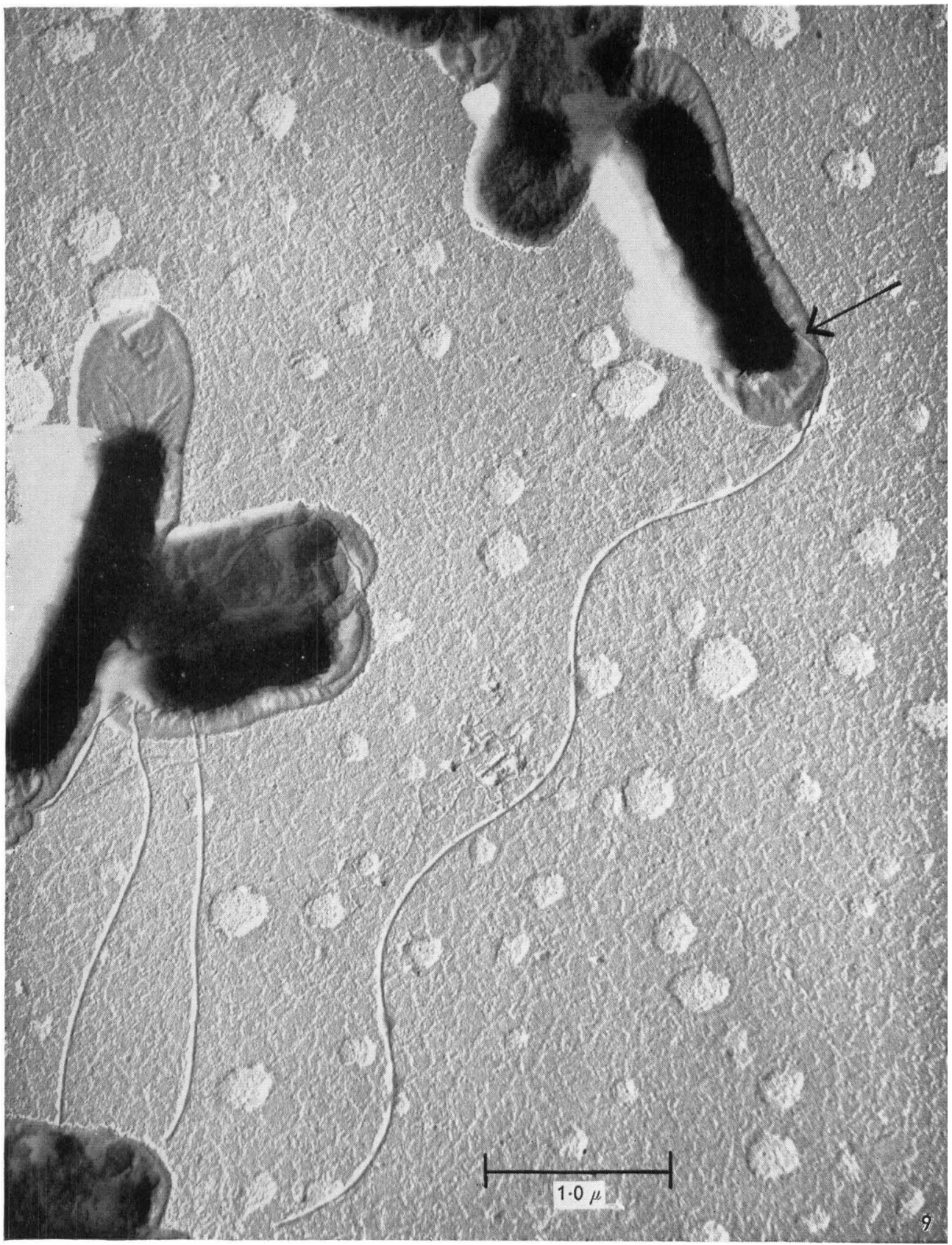

A. C. HAYWARD aND W. HODGKISS 